\title{
The Effects of Acute Hypoxia on Tissue Oxygenation and Circulating Alarmins in Healthy Adults
}

\author{
C. J. BOOS ${ }^{1,2,3,4}$, C. M. LAMB ${ }^{4}$, M. MIDWINTER ${ }^{4}$, A. MELLOR ${ }^{4,5}$, D. R. WOODS ${ }^{3,4,6,7}$, \\ M. HOWLEY ${ }^{5}$, T. STANSFIELD ${ }^{4}$, M. FOSTER ${ }^{4}$, J. P. O'HARA ${ }^{3}$
}

${ }^{1}$ Department of Cardiology, Poole Hospital NHS Foundation Trust, Poole, UK, ${ }^{2}$ Department of Postgraduate Medical Education, Bournemouth University, Bournemouth, UK, ${ }^{3}$ Research Institute for Sport, Physical Activity and Leisure, Leeds Beckett University, Leeds, UK, ${ }^{4}$ Defence Medical Services, Lichfield, UK, ${ }^{5}$ James Cook University Hospital, Middlesbrough, UK, ${ }^{6}$ Northumbria and Newcastle NHS Trusts, Wansbeck General and Royal Victoria Infirmary, Newcastle upon Tyne, UK, ${ }^{7}$ University of Newcastle, Newcastle upon Tyne, UK

Received August 10, 2017

Accepted February 19, 2018

On-line May 10, 2018

\begin{abstract}
Summary
The binding of high-mobility group box-1 (HMGB-1) to the membrane receptor for advanced glycation end-products (mRAGE) is a key early mediator of non-infectious inflammation and its triggers include ischaemia/hypoxia. The effects of acute hypoxia on soluble RAGE (sRAGE) are unknown. Fourteen healthy adults (50\% women; $26.6 \pm 3.8$ years) were assessed at baseline normoxia (TO), followed by four time-points (T90, 95, 100 and $180 \mathrm{~min}$ ) over three hours of continuous normobaric hypoxia ( $\mathrm{NH}, 4,450 \mathrm{~m}$ equivalent) and again $60 \mathrm{~min}$ after return to normoxia (T240). A 5-min exercise step test was performed during $\mathrm{NH}$ at T90. Plasma concentrations of HMGB-1, SRAGE VCAM-1, ICAM-1, VEGF IL-8 and IL-13 were measured using venous blood. Arterial and tissue oxygen saturations were measured using pulse oximetry $\left(\mathrm{SpO}_{2}\right)$ and near-infrared spectroscopy $\left(\mathrm{StO}_{2}\right)$, respectively. $\mathrm{NH}$ led to a significant reduction in $\mathrm{SpO}_{2}, \mathrm{StO}_{2}$, sRAGE and VEGF, which was compounded by exercise, before increasing to baseline values with normoxic restoration (T240). $\mathrm{NH}$-exercise led to a paired increase in HMGB-1. SRAGE inversely correlated with HMGB-1 ( $r=-0.32$; $p=0.006)$, heart rate $(r=-0.43 ; p=0.004)$ but was not linked to $\mathrm{SpO}_{2}$ or $\mathrm{StO}_{2}$. In conclusion, short-term $\mathrm{NH}$ leads to a fall in SRAGE and VEGF concentrations with a transient rise post $\mathrm{NH}$-exercise in HMGB-1.
\end{abstract}

\section{Key words}

Acute hypoxia • Normobaric • Alarmins • SRAGE • Exercise

\section{Corresponding author}

C. J. Boos, Department of Cardiology, Poole Hospital NHS Foundation Trust, Longfleet Rd., Poole, Dorset, BH15 2JB, UK. Fax: +44 120244 2754. E-mail: christopherboos@hotmail.com

\section{Introduction}

There is evidence to suggest that acute hypoxia can trigger a pro-inflammatory response, however the published data are inconsistent (Tamura et al. 2002), Rohm et al. 2015, Iglesias et al. 2015, Burki and Tetenta 2104). Research has tended to focus on more traditional infection-related inflammatory cytokines/biomarkers, yet hypoxia reflects a non-infectious stimulus (Burki and Tetenta 2014). Hence, the assessment of other 'sterile' pro-inflammatory mediators and their receptors may be more relevant to this environment (Rider et al. 2012).

The damage-associated molecular patterns (DAMPs; alarmins) are particularly attractive in this regard as they are associated with non-infectious inflammatory responses such as ischaemia, acute hypoxia and trauma as well systemic inflammatory conditions (Bianchi 2007, Feldman et al. 2015). They are released by stressed or tissue damaged cells leading to the early activation of endogenous danger signals and inflammatory responses (Bianchi 2007). One of the best known DAMPs is high mobility group box-1(HMGB-1). 
Its activation receptor includes the transmembrane, multipattern-recognition receptor for advanced glycation end products (mRAGE) (Sparvero et al. 2009 Alexiou et al. 2010). HMGB-1 binding to mRAGE leads to immediate and prolonged inflammatory response and increased expression of cellular adhesion molecules (e.g. vascular cell adhesion molecule-1 [VCAM-1] and selectins) and angiogenic factors (e.g. vascular endothelial growth factor [VEGF]). Limited available evidence suggests that HMGB-1 production is upregulated during hypoxia and that RAGE activation contributes the development of hypoxia-induced pulmonary hypertension (Jia et al. 2017). Membrane bound RAGE is very difficult to measure in vivo, however soluble forms of RAGE (sRAGE) also exist and possess a similar affinity for ligands to mRAGE. It is formed either by alternative splicing of RAGE mRNA or by proteolytic cleavage of full-length mRAGE protein. Whilst the actions of sRAGE have not been fully elucidated, it appears to elicit a counter-regulatory role by acting as a 'decoy receptor' to neutralise AGE-mediated inflammation and damage. Reduced levels of sRAGE have been identified across a number of known inflammatory conditions and appear to be inversely related to disease activity state (Raucci $e t$ al. 2008, Prasad 2014). Animal data has shown that sRAGE may be protective against ischaemia reperfusion injury and hypoxia-induced right ventricular pressure increase, raising several potential translational clinical applications (Farmer et al. 2014, Zeng et al. 2004).

In this study we aimed to investigate, for the first time, the effects of effect of acute hypoxia on sRAGE its relationship to tissue oxygenation and other pro- and antiinflammatory mediators including HMGB-1 in healthy humans.

\section{Methods}

\section{Study population}

This was a prospective observational study of 14 fit and healthy serving British military adults. All participants were required to have abstained from caffeine, alcohol, non-steroidal anti-inflammatory drugs and smoking for $>12 \mathrm{~h}$ prior to the study and to have avoided strenuous physical activity for $48 \mathrm{~h}$ prior to the experiment. Confirmation of health status was confirmed following a detailed health questionnaire and baseline echocardiogram to confirm suitability for inclusion. Pregnant women and persons suffering from an intercurrent illness were excluded.
Ethics

The study was approved by the Ministry of Defence Research and Medical Ethics Committee and was conducted according to the standards of the declaration of Helsinki. All subjects underwent written informed consent for the study.

\section{Study protocol}

Subjects were examined across five separate continuous time points. The first baseline measured time point was at normoxic rest at near sea level $(113 \mathrm{~m})$ prior to acute nomobaric hypoxic (NH) exposure (T0). Four further time points were assessed during exposure to continuous $\mathrm{NH}$ in an experimental $\mathrm{NH}$ chamber at 90 (T90), 95 (T95), 100 (T100) and 180 (T180) min. The subjects were then studied for the final time $60 \mathrm{~min}$ post hypoxia (240 min, T240) under identical normoxic conditions to the baseline assessments.

The NH chamber (TISS, Alton, UK and Sporting Edge, Sherfield on Loddon, UK) was set to an $\mathrm{FiO}_{2}$ of $\sim 11.4 \%$ (considering daily fluctuations of barometric pressure) which was equivalent to an altitude of $4,450 \mathrm{~m}$ $\left(\mathrm{PiO}_{2} 81.50 \mathrm{~mm} \mathrm{Hg}\right.$ ) (Conkin 2011). In order to identify the potentially compounding effects of exercise, all subjects underwent a 5-min step test at minutes 90-95 of the $180 \mathrm{~min}$ during $\mathrm{NH} . \mathrm{SpO}_{2}, \mathrm{StO}_{2}$ and only were obtained at end exercise (T95) to assess the intensity of exercise stimulus under NH. The chamber temperature was controlled at $21^{\circ} \mathrm{C}$ throughout the study.

\section{Physiological measurements}

Resting recordings of peripheral arterial oxygen saturations $\left(\mathrm{SpO}_{2}\right)$ were performed from a sensor placed at the finger tip of either index finger using a Nellcor N-20P pulse oximeter (Nellcor Puritan Bennett, Coventry, UK). Tissue oxygen saturations $\left(\mathrm{StO}_{2}\right)$ were measured using near infrared spectroscopy as previously described (NIRS; INVOS, Somenetics, Michigan, USA) with sampling from the right frontal area of the brain and right deltoid muscle, two finger breadths above the muscle's insertion on the humerus (Scheeran et al. 2012).

\section{Blood sampling}

Venous blood samples were drawn from an indwelling cannula which was inserted into the antecubital fossa for the duration of the study. The samples were drawn into EDTA bottles and centrifuged at $10,000 \mathrm{rpm}$ for $5 \mathrm{~min}$ immediately on site and the supernatant plasma was frozen at $-80^{\circ} \mathrm{C}$ for later 
analysis. Samples were analysed with enzyme linked immunosorbent assays (ELISAs) for the presence of HMGB-1 (Luminex ELISA, IBL International, Hamburg, Germany), sRAGE (DuoSet ELISA, R\&D Systems, Oxford, UK) and for VCAM (Vascular cell adhesion molecule)-1, ICAM (Intercellular adhesion molecule)-1, VEGF (Vascular endothelial growth factor) and soluble E-Selectin. Multiplex technology was used to measure interleukin (IL)-8 and IL-13 using a commercial multiplex kit (R\&D Systems). Standard curves for the ELISAs were produced using the spreadsheet program Excel (Microsoft). Plasma concentrations were then obtained by interpolation from these standard curves using the statistical software program Prism (GraphPad Software, San Diego, CA, USA).

\section{Statistical methods}

Data were analysed using GraphPad InStat version 3.05 and SPSS version 22. The figures were generated using GraphPad Prism version 4.00 for Windows. Data inspection and the Kolmogorov-Smirnov test was undertaken to assess normality of all continuous data which was presented as the mean \pm standard deviation and as median \pm inter-quartile range for all parametric and non-parametric data, respectively. Categorical variables were compared using Fishers Exact test. Comparison of unpaired data was performed using an unpaired $T$ test and a Mann-Whitney test for parametric and non-parametric data, respectively. Paired two group comparisons of continuous data were performed using a paired test and Wilcoxon matchedpairs signed-ranks test for parametric and non-parametric data, respectively. The time-dependent changes in continuous data were assessed with repeated measures ANOVA for normally distributed data, with the Tukey post-test (comparing with baseline) for all significant results. Repeated measures of non-parametric continuous data were performed using the Friedman test with the Dunn post-test (comparing with baseline) for all significant results. If a significant overall main effect for time (hypoxia) was found in circulating biomarker concentrations an additional exploratory analysis was undertaken using a two-way factorial repeated measures ANOVA. This was done to discern whether there was an additional main effect for sex (men vs. women) on the changes in circulating markers (e.g. sRAGE) and any evidence of its potential interaction (sex x time/hypoxia) on their concentrations. Correlations were performed using Pearson and Spearman rank correlation $( \pm 95 \%$ confidence interval, CI) for parametric and non-parametric data, respectively. A two-sided $p$ value of $<0.05$ was considered significant.

\section{Sample size calculation}

In a previous acute hypoxia study Iglesias et al. (2015) observed a significant increase in a number of proinflammatory cytokines (e.g. hsCRP and $\mathrm{TNF} \alpha$ ) in 10 healthy subjects exposed to a simulated altitude of $4,000 \mathrm{~m}$. Whilst there have been no healthy human studies that have assessed the effects of acute hypoxia on sRAGE levels, in a previous animal study Gopal et al. 2015) demonstrated a significant increase in sRAGE among 8 mice over 21 days of simulated hypoxia $\left(\mathrm{FiO}_{2}\right.$ down to $\left.8 \%\right)$. Hence, we estimated that a sample size of 14 subjects exposed to three hours of simulated hypoxia to an equivalent altitude of at least $4,000 \mathrm{~m}$ should provide both sufficient power and a hypoxic stimulus to detect a potential change in sRAGE if genuine. Given the recognised potential differences in expression and concentrations of various circulating biomarkers between men and women and in their physiological responses to hypoxia we aimed to recruit an equal number of men and women (Boos et al. 2016a, Planchard et al. 2009).

\section{Results}

The average age of the 14 Caucasian subjects was 26.6 \pm 3.8 (range 21-33) years, with an even number of men $(n=7,50 \%)$ and women $(n=7,50 \%)$. All participants completed the entire study and none were on regular medication. All women were on the oral contraceptive pill. The mean body mass index was $24.7 \pm 2.7 \mathrm{~kg} / \mathrm{m}^{2}$ and only one subject (7.1\%) was a current smoker.

Changes in physiological measures and oxygen saturation

Acute $\mathrm{NH}$ led to a significant increase in resting heart rate (Table 1). Heart rate significantly rose from $73.9 \pm 11.0$ to $139.1 \pm 18.9 / \mathrm{min}$ with exercise $(\mathrm{p}<0.0001)$.

Frontal $\mathrm{StO}_{2}$ was lower than deltoid $\mathrm{StO}_{2}$ at all time points and were both lower than peripheral $\mathrm{SpO}_{2}$ values (Fig. 1, Table 1). Peripheral $\mathrm{SpO}_{2}$, deltoid and frontal lobe $\mathrm{StO}_{2}$ all significantly fell during acute NH compared with baseline normoxia (T0). This fall was greatest immediately post exercise and all values returned to near baseline levels at T240 when normoxia was 
restored (Table 1). Peripheral $\mathrm{SpO}_{2}$ correlated with both deltoid ( $\mathrm{r}=0.53 ; 95 \% \mathrm{CI}: 0.37$ to 0.66$)$ and frontal $(\mathrm{r}=0.72 ; 95 \% \mathrm{CI}: 0.60$ to $0.81: \mathrm{p}<0.0001) \mathrm{StO}_{2}$. Deltoid and frontal $\mathrm{StO}_{2}$ were significantly correlated $(\mathrm{r}=0.40$; 0.21 to $0.55 ; \mathrm{p}<0.0001)$.

\section{Alarmin/cytokine level changes}

There was a significant main effect for time (and hypoxia) on plasma sRAGE and VEGF concentrations, which significantly fell during acute $\mathrm{NH}$ and returned to near baseline values when normoxia was restored at T240 (Table 1, Figs 2 and 3). Although sRAGE concentrations tended to be higher and VEGF concentrations lower there was no significant main effect for sex (men versus women) or sex-time (hypoxic exposure) interaction on sRAGE and VEGF concentrations. There was a paired fall in IL-13 from T90 to T100 $(p=0.04)$ and an increase in HMGB-1 from T90 to T100 $(p=0.049)$ but again no main effect for sex. The plasma levels of IL-8, VCAM-1 and ICAM-1 did not change significantly over time (Table 1). sRAGE non-significantly increased (=15.4\%) with exercise (to 100 vs. T90) (Table 1, Fig. 2).

sRAGE inversely correlated with heart rate $(\mathrm{r}=-0.43 ;-0.66$ to $-0.14: \mathrm{p}=0.004)$ and HMGB-1 concentrations ( $r=-0.32 ;-0.52$ to $-0.09: \mathrm{p}=0.006)$. There was no significant correlation between sRAGE concentrations and peripheral or tissue oxygen saturation. $\mathrm{SpO}_{2}$ inversely correlated with heart rate $(\mathrm{r}=-0.70 ;-0.81$ to $-0.55 ; \mathrm{p}<0.0001)$.

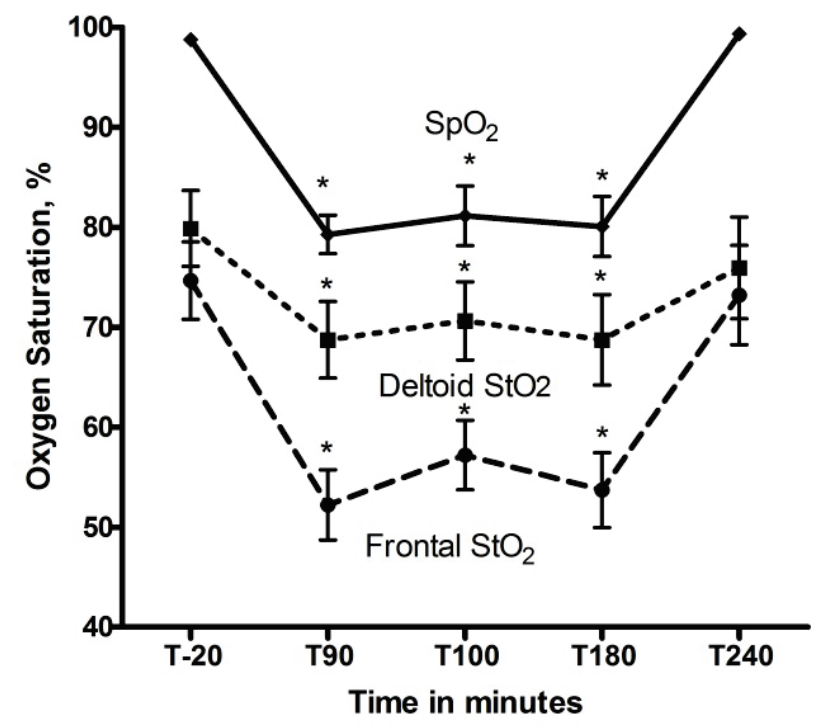

Fig. 1. Changes (mean, $95 \% \mathrm{CI}$ ) in peripheral $\left(\mathrm{SpO}_{2}\right)$ and deltoid and frontal tissue oxygen $\left(\mathrm{StO}_{2}\right)$ Saturations with normoxia (T0 and T240) and $3 \mathrm{~h}$ of hypoxia (T90, T100 and T180); * significant change vs. baseline (T0).

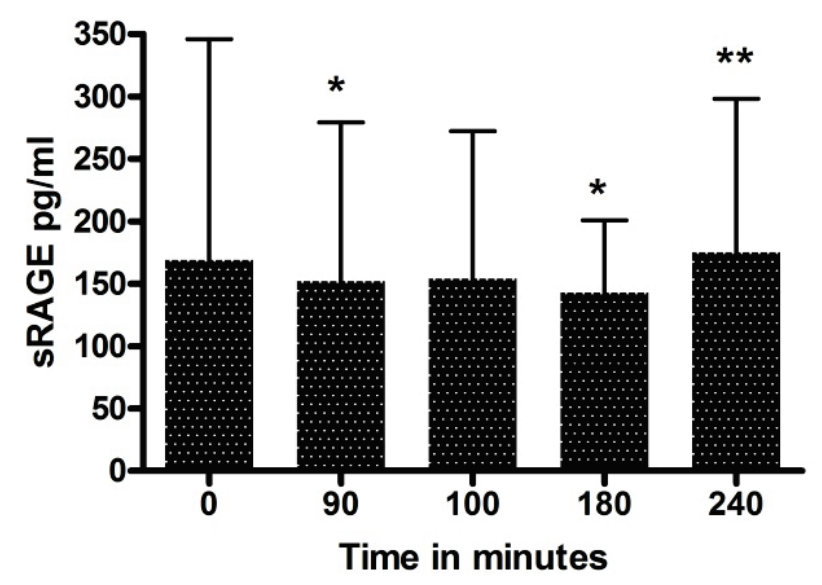

Fig. 2. Changes in SRAGE (median, interquartile range) with acute normobaric hypoxia (T90, T100 and T180); * significant change vs. baseline (T0); ** vs. T180.

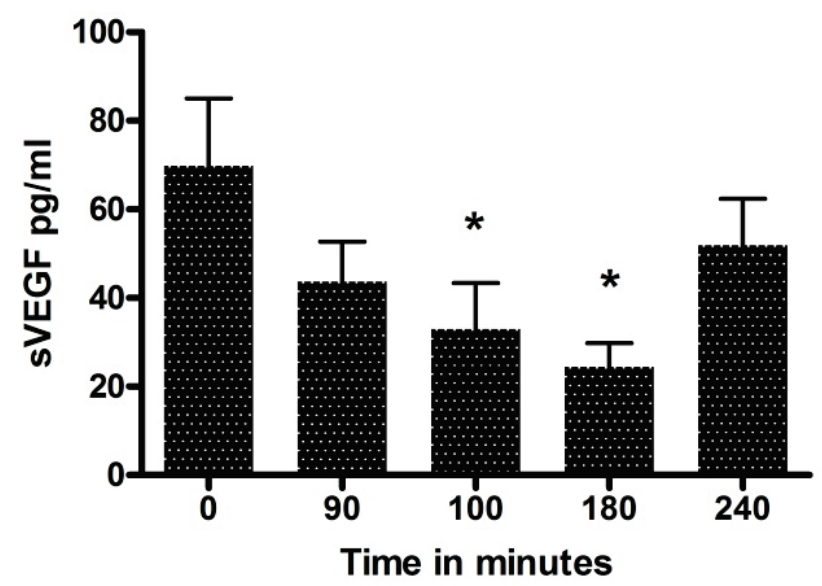

Fig. 3. Changes in VEGF (mean, standard deviation) with acute normobaric hypoxia (T90, T100 and T180); * significant change vs. baseline (TO).

\section{Discussion}

This is the first human study to assess the effect of acute NH on the levels of sRAGE and its relationship to peripheral and tissue oxygenation. NH led to a significant increase in heart rate and fall in peripheral arterial $\left(\mathrm{SpO}_{2}\right)$ and tissue oxygen $\left(\mathrm{StO}_{2}\right)$ saturation and a reduction in sRAGE and VEGF levels compared with baseline sea level normoxia. Brief exercise during $\mathrm{NH}$ was associated with a transient yet significant fall in IL-13 and an increase in HMGB-1 concentrations.

In this study, $\mathrm{StO}_{2}$ was, as to be expected, consistently lower than $\mathrm{SpO}_{2}$ with normoxia and acute $\mathrm{NH}$. This reflects the fact that $\mathrm{SpO}_{2}$ measures arterial oxygen saturation whereas $\mathrm{StO}_{2}$ assesses tissue oxygen saturation and a degree of deoxygenated blood (Subudhi et al. 2007). Frontal (cerebral) $\mathrm{StO}_{2}$ was, however, lower than that measured over the deltoid muscle at all time 


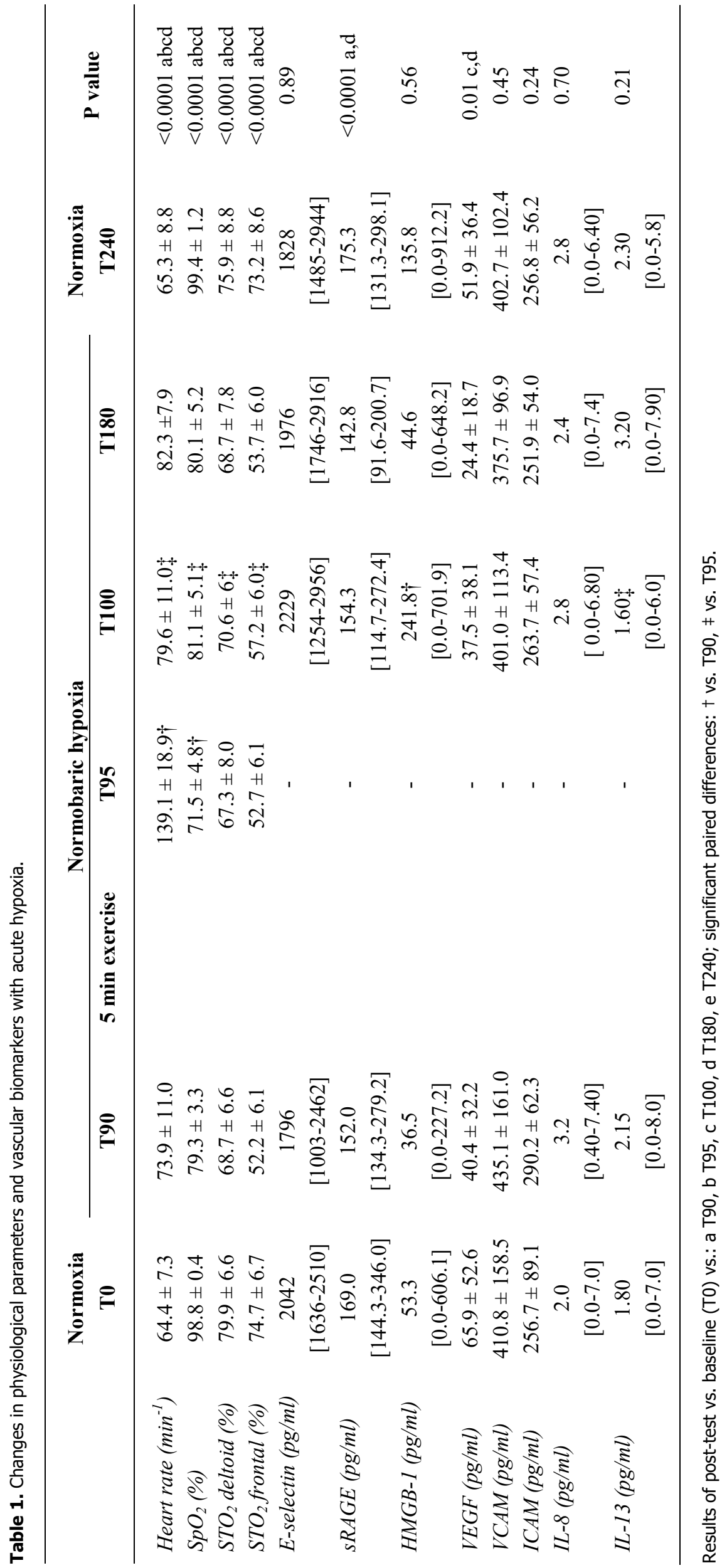


points. This finding supports the limited published comparative data and likely reflects the greater oxygen extraction in cerebral versus deltoid muscle tissue (Rupp et al. 2013). Despite generating a significant hypoxic stimulus we failed to observe a significant increase in any of the inflammatory markers measured with $\mathrm{NH}$, apart from a borderline rise in HGMB-1 following brief exercise. This finding was unexpected given the cited links between hypoxia and inflammation (Tamura et al. 2002, Rohm et al. 2015, Iglesias et al. 2015). However, there is contrary data where a hypoxia-inflammatory link has not been demonstrated (Tamura et al. 2002, Burki and Tetenta 2014, Woodside et al. 2014, Ylimaz et al. 2016). These differences in study findings could be explained by dissimilarities in study population (age and sex), methodology including the duration, type (normobaric versus hypobaric hypoxia) and severity of hypoxia and in the biomarkers studied. In fact, the most consistent data have been with terrestrial high altitude, where a number of confounding factors may be more relevant (Boos et al. 2016b, West 2012). These include the greater physical (e.g. cold) and exercise challenge, sleep deprivation and increased psychological stress (Boos et al. 2016b, West 2012).

In this study we introduced a short duration of exercise using a 5 -min step test over the $90-95^{\text {th }} \mathrm{min}$ of $\mathrm{NH}$. This was undertaken in order to assess the relative impact of exercise during acute $\mathrm{NH}$ on arterial/tissue oxygenation and vascular inflammation. $\mathrm{SpO}_{2}$ fell further on exercise whereas tissue oxygenation (both deltoid and frontal $\mathrm{StO}_{2}$ ) was maintained. This would appear to suggest preservation of tissue oxygenation and its microcirculation compared with arterial oxygenation during exercise (Ide and Secher 2000). By five minutes post exercise and hence its early recovery (T100) both $\mathrm{SpO}_{2}$ and $\mathrm{StO}_{2}$ had significantly increased compared with the values at end exercise (T95). This mild increase in both $\mathrm{SpO} 2$ and $\mathrm{StO}_{2}$ post exercise could reflect local vasodilatation or a shift in the oxygen dissociation curve to repay an oxygen debt accumulated during exercise.

RAGE is a multi-ligand, pattern recognition receptor, allowing it to act as an early sensor of DAMPs and act as an early trigger receptor in acute inflammation (Lin et al. 2006, Bapp et al. 2008). Once activated, it initiates transcription factor pathways and expression of various pro-inflammatory cytokines. While the full RAGE is membrane bound, it is the extracellular portion that is converted to the soluble form in the circulation (sRAGE) by cleavage and shedding from the membrane bound form. This occurs at a steady background rate but is increased by ligand binding (Raucci et al. 2008). Reduced plasma levels of sRAGE have been reported in a number of acute and chronic 'sterile' inflammatory conditions and have been linked to disease severity (Prasad 2014, Maillard-Lefebvre et al. 2009). However, the data does appear to be conflicting and depends on the study population, disease state and its chronicity (Nakamura et al. 2011, Prasad 2014).

We observed a fall in sRAGE levels with acute hypoxia compared with baseline normoxia. This fall was not different among men and women. RAGE engages numerous ligands and its signalling is highly complex and influenced by a multitude of different factors including ligand identity/type and concentration, cell type as well as the surface concentration of RAGE. Furthermore, sRAGE reflects both cleaved and endogenous secretary RAGE and the relative proportion and activity of each can be highly variable (Tang et al. 2009). Soluble RAGE is known to neutralize AGE-mediated damage by acting as a decoy and competitive inhibitor of ligand-RAGE interaction and downstream inflammatory cascades (Lindsey et al. 2009, Kalea et al. 2009). Hence, we speculate that the reduction in sRAGE observed in this study could reflect sequestering of AGEs, reduced VEGF expression and might explain the failure of HGMB-1 and other pro-inflammatory levels to rise (Prasad 2014, Keirdorf and Fritz 2014).

The exercise stimulus in this study as brief but intensive and led to a $100 \%$ increase in heart rate and further arterial desaturation and was associated with a transient but non-significant increase in sRAGE. These findings are consistent with a recent study by Danzig et al. (2005), in which sRAGE was shown to non-significantly but similarly increase following brief high-intensity exercise (bicycle) in both healthy controls $(n=22)$ and participants with a previous history of coronary disease. Similar to our study they measured sRAGE levels at five minutes post exercise. There are no previous comparative studies with acute hypoxia in healthy humans. In one of the only studies of hypoxia on sRAGE levels it was shown that sustained hypoxia (21 days) led to an increased gene expression of RAGE in lung tissue and a rise in circulating sRAGE of mice (Gopal et al. 2015). In contrast to this study, we studied a much shorter period of hypoxia and thus cannot discount the possibility that sRAGE levels could have risen with longer much longer hypoxic exposure. The fact 
that sRAGE levels fell with acute hypoxia before increasing to near baseline concentrations on return to normoxia does support a genuine short term effect of $\mathrm{NH}$ on sRAGE.

VEGF is best known as a mitogen, acting mainly on the vascular endothelium. It is responsible for both pathological and physiological angiogenesis, vasodilatation and capillary hyperpermeability in response to localised hypoxia (Ferrara 2009). VEGF has been shown to act on multiple different inflammatory cells; mediating their survival, proliferation and differentiation (Maharaj and $\mathrm{d}^{\prime}$ Amore 2007). Its precise function as an inflammatory mediator and cytokine is unknown but hypoxia is known to be one of the most potent stimuli for VEGF expression (Maharaj and d'Amore 2007). Increased free plasma VEGF levels have been linked to worsening hypoxia and to the development of acute mountain sickness in a previous study (Tissot van Patot et al. 2005). However the wider published data has been inconsistent with several studies reporting a rise and others either a fall or no change in circulating VEGF following acute hypoxia (Pavlicek et al. 2000, Oltmanns et al. 2005, Gunga et al. 1999).

We identified a fall in VEGF with $\mathrm{NH}$ which became significant by $100 \mathrm{~min}$ of $\mathrm{NH}$, with restoration of baseline values on return to normoxia. This change was not influenced by the subject's sex. There are several potential mechanisms to explain this observed reduction in VEGF with NH. The fact that we measured short term hypoxia and unbound circulating VEGF may be important. It has been proposed that a decrease in VEGF with acute hypoxia might reflect simultaneous upregulation of the soluble VEGF receptor (sFlt-1) which traps soluble VEGF as well as inhibiting its formation (Oltmanns et al. 2005). Another proposed mechanism could be hypoxia induced glucose intolerance, which has been reported to inhibit VEGF generation (Oltmanns et al. 2004). Unfortunately, we did not measure glucose concentration during this study. One of the key functions of VEGF is to stimulate the mobilisation of endothelial progenitor cells (EPC) from bone marrow to support angiogenesis. It has been recently shown that acute $\mathrm{NH}$ (equivalent to 4,100 m) led to a reduction in EPCS and increased EPC apoptosis and markers of oxidative stress in 10 healthy adults, which became significant by $\geq 30 \mathrm{~min}$ of $\mathrm{NH}$ exposure (Colombo et al. 2012). These changes may be related to a reduction of VEGF with acute $\mathrm{NH}$.

This study has additional strengths and limitations that should be acknowledged. The fact that we studied an equal number of men and women of similar age, a broad range of biomarkers and their relationship to both peripheral and tissue oxygenation are major strengths of this study. However, the sample size in this study is relatively small with significant variance around several measured markers. Hence we cannot exclude the fact that we may not have appreciated a genuine difference due to the sample size. However, our sample size is similar or larger than majority of published work and was sufficient to identify significant differences in sRAGE and VEGF with hypoxia across a number of measured time points. Whilst we did measured three time points at T90, T100 and T180 during acute NH is could be argued that an earlier acute change could have been missed as the first sampling time point was 90 min into acute $\mathrm{NH}$ exposure and arguably during a more steady state.

In conclusion, acute $\mathrm{NH}$ led to a significant reduction in both peripheral and arterial tissue oxygen saturation and an associated fall in sRAGE and VEGF concentrations. Brief exercise during hypoxia led to a transient fall in IL-13 and increase in HMGB-1 concentrations and an increase in both peripheral and tissue oxygen saturation.

\section{Conflict of Interest}

There is no conflict of interest.

\section{Acknowledgements}

The authors would like to thank the Drummond Foundation, Leeds Beckett University, the Defence Medical Services and the Surgeon General's Department for their support. The research reported in this study was supported by the Surgeon General, UK and the Drummond Foundation. The content is solely the responsibility of the authors and does not necessarily represent the official views of the Defence Medical Services.

\section{References}

ALEXIOU P, CHATZOPOULOU M, PEGKLIDOU K, DEMOPOULOS VJ: RAGE: a multi-ligand receptor unveiling novel insights in health and disease. Curr Med Chem 17: 2232-2252, 2010. 
BIANCHI ME: DAMPs, pamps and alarmins: all we need to know about danger. J Leukoc Biol 81: 1-5, 2007.

BOOS CJ, MELLOR A, O'HARA JP, TSAKIRIDES C, WOODS DR: The effects of sex on cardiopulmonary responses to acute normobaric hypoxia. High Alt Med Biol 17: 108-115, $2016 \mathrm{a}$.

BOOS CJ, WOODS DR, VARIAS A, BISCOCHO S, HESELTINE P, MELLOR AJ: High altitude and acute mountain sickness and changes in circulating endothelin-1, interleukin-6, and interleukin-17a. High Alt Med Biol 17: 25-31, $2016 \mathrm{~b}$.

BOPP C, BIERHAUS A, HOFER S, BOUCHON A, NAWROTH PP, MARTIN E, WEIGAND MA: Bench-to-bedside review: the inflammation-perpetuating pattern-recognition receptor RAGE as a therapeutic target in sepsis. Crit Care 12: 201, 2008.

BURKI NK, TETENTA SU: Inflammatory response to acute hypoxia in humans. Pulm Pharmacol Ther 27: 208-211, 2014.

COLOMBO E, MARCONI C, TADDEO A, CAPPELLETTI M, VILLA ML, MARZORATI M, PORCELLI S, VEZZOLI A, DELLA BELLA S: Fast reduction of peripheral blood endothelial progenitor cells in healthy humans exposed to acute systemic hypoxia. J Physiol 590: 519-532, 2012.

CONKIN J: PH2O and simulated hypobaric hypoxia. Aviat Space Environ Med 82: 1157-1158, 2011.

DANZIG V, MÍKOVÁ B, KUCHYNKA P, BENÁKOVÁ H, ZIMA T, KITTNAR O, SKRHA J, LINHART A, KALOUSOVÁ M: Levels of circulating biomarkers at rest and after exercise in coronary artery disease patients. Physiol Res 59: 385-392, 2010.

FARMER DG, EWART MA, MAIR KM, KENNEDY S: Soluble receptor for advanced glycation end products (sRAGE) attenuates haemodynamic changes to chronic hypoxia in the mouse. Pulm Pharmacol Ther 29: 7-14, 2014.

FELDMAN N, ROTTER-MASKOWITZ A, OKUN E: DAMPs as mediators of sterile inflammation in aging-related pathologies. Ageing Res Rev 24: 29-39, 2015.

FERRARA N: Vascular endothelial growth factor. Arterioscler Thromb Vasc Biol 29: 789-791, 2009.

GOPAL P, GOSKER HR, THEIJE CC, EURLINGS IM, SELL DR, MONNIER VM, REYNAERT NL: Effect of chronic hypoxia on RAGE and its soluble forms in lungs and plasma of mice. Biochim Biophys Acta 1852: 992-1000, 2015.

GUNGA HC, KIRSCH K, RÖCKER L, BEHN C, KORALEWSKI E, DAVILA EH, ESTRADA MI, JOHANNES B, WITTELS P, JELKMANN W: Vascular endothelial growth factor in exercising humans under different environmental conditions. Eur J Appl Physiol Occup Physiol 79: 484-490, 1999.

IDE K, SECHER NH: Cerebral blood flow and metabolism during exercise. Prog Neurobiol 61: 397-414, 2000.

IGLESIAS D, GÓMEZ ROSSO L, VAINSTEIN N, MEROÑO T, LEZÓN C, BRITES F: Vascular reactivity and biomarkers of endothelial function in healthy subjects exposed to acute hypobaric hypoxia. Clin Biochem $\mathbf{4 8}$ : 1059-1063, 2015.

JIA D, HE Y, ZHU Q, LIU H, ZUO C, CHEN G, YU Y, LU A: RAGE-mediated extracellular matrix proteins accumulation exacerbates HySu-induced pulmonary hypertension. Cardiovasc Res 113: 586-597, 2017.

KALEA AZ, SCHMIDT AM, HUDSON BI: RAGE: a novel biological and genetic marker for vascular disease. Clin Sci (Lond) 116: 621-637, 2009.

KIERDORF K, FRITZ G: RAGE regulation and signaling in inflammation and beyond. J Leukoc Biol 94: 55-68, 2013.

MAHARAJ AS, D'AMORE PA: Roles for VEGF in the adult. Microvasc Res 74: 100-113, 2007.

MAILLARD-LEFEBVRE H, BOULANGER E, DAROUX M, GAXATTE C, HUDSON BI, LAMBERT M: Soluble receptor for advanced glycation end products: a new biomarker in diagnosis and prognosis of chronic inflammatory diseases. Rheumatology (Oxford) 48: 1190-1196, 2009.

NAKAMURA T, SATO E, FUJIWARA N, KAWAGOE Y, MAEDA S, YAMAGISHI S: Increased levels of soluble receptor for advanced glycation end products (srage) and high mobility group box 1 (HMGB1) are associated with death in patients with acute respiratory distress syndrome. Clin Biochem 44: 601-604, 2011.

OLTMANNS KM, GEHRING H, RUDOLF S, SCHULTES B, HACKENBERG C, SCHWEIGER U, BORN J, FEHM HL, PETERS A: Acute hypoxia decreases plasma VEGF concentration in healthy humans. Am J Physiol Endocrinol Metab 290: E434-E439, 2006. 
PAVLICEK V, MARTI HH, GRAD S, GIBBS JS, KOL C, WENGER RH, GASSMANN M, KOHL J, MALY FE, OELZ O, KOLLER EA, SCHIRLO C: Effects of hypobaric hypoxia on vascular endothelial growth factor and the acute phase response in subjects who are susceptible to high-altitude pulmonary oedema. Eur J Appl Physiol 81: 497-503, 2000.

PLANCHARD D, LORIOT Y, GOUBAR A, COMMO F, SORIA JC: Differential expression of biomarkers in men and women. Semin Oncol 36: 553-565, 2009.

PRASAD K: Low levels of serum soluble receptors for advanced glycation end products, biomarkers for disease state: myth or reality. Int J Angiol 23: 11-16, 2014.

RAUCCI A, CUGUSI S, ANTONELLI A, BARABINO SM, MONTI L, BIERHAUS A, REISS K, SAFTIG P, BIANCHI ME: A soluble form of the receptor for advanced glycation endproducts (RAGE) is produced by proteolytic cleavage of the membrane-bound form by the sheddase a disintegrin and metalloprotease 10 (ADAM10). FASEB J 22: 3716-3727, 2008.

RIDER P, KAPLANOV I, ROMZOVA M, BERNARDIS L, BRAIMAN A, VORONOV E, APTE RN: The transcription of the alarmin cytokine interleukin-1 alpha is controlled by hypoxia inducible factors 1 and 2 alpha in hypoxic cells. Front Immunol 3: 290, 2012.

ROHM I, RATKA J, PISTULLI R, GOEBEL B, GECKS T, FIGULLA HR, YILMAZ A, JUNG C: Impact of systemic normobaric short-term hypoxia on pro-inflammatory and anti-inflammatory cytokines in healthy volunteers. Clin Lab 61: 1053-1059, 2015.

RUPP T, LETI T, JUBEAU M, MILLET GY, BRICOUT VA, LEVY P, WUYAM B, PERREY S, VERGES S: Tissue deoxygenation kinetics induced by prolonged hypoxic exposure in healthy humans at rest. J Biomed Opt 18: 095002, 2013.

SCHEEREN TW, SCHOBER P, SCHWARTE LA: Monitoring tissue oxygenation by near infrared spectroscopy (NIRS): background and current applications. J Clin Monit Comput 26: 279-287, 2012.

SPARVERO LJ, ASAFU-ADJEI D, KANG R, TANG D, AMIN N, IM J, RUTLEDGE R, LIN B, AMOSCATO AA, ZEH HJ, LOTZE MT: RAGE (Receptor for Advanced Glycation Endproducts), RAGE ligands, and their role in cancer and inflammation. $J$ Transl Med 7: 17, 2009.

SUBUDHI AW, DIMMEN AC, ROACH RC: Effects of acute hypoxia on cerebral and muscle oxygenation during incremental exercise. J Appl Physiol (1985) 103: 177-183, 2007.

TAMURA DY, MOORE EE, PARTRICK DA, JOHNSON JL, OFFNER PJ, SILLIMAN CC: Acute hypoxemia in humans enhances the neutrophil inflammatory response. Shock 17: 269-273, 2002.

TANG SC, YEH SJ, TSAI LK, HU CJ, LIEN LM, PENG GS, YANG WS, CHIOU HY, JENG JS: Cleaved but not endogenous secretory RAGE is associated with outcome in acute ischemic stroke. Neurology 86: 270-276, 2016.

TISSOT VAN PATOT MC, LEADBETTER G, KEYES LE, BENDRICK-PEART J, BECKEY VE, CHRISTIANS U, HACKETT P: Greater free plasma VEGF and lower soluble VEGF receptor-1 in acute mountain sickness. J Appl Physiol (1985) 98: 1626-1629, 2005.

WEST JB: High-altitude medicine. Am J Respir Crit Care Med 186: 1229-1237, 2012.

WOODSIDE JD, GUTOWSKI M, FALL L, JAMES PE, MCENENY J, YOUNG IS, OGOH S, BAILEY DM: Systemic oxidative-nitrosative-inflammatory stress during acute exercise in hypoxia; implications for microvascular oxygenation and aerobic capacity. Exp Physiol 99: 1648-1662, 2014.

YILMAZ A, RATKA J, ROHM I, PISTULLI R, GOEBEL B, ASADI Y, PETRI A, KIEHNTOPF M, FIGULLA HR, JUNG C: Decrease in circulating plasmacytoid dendritic cells during short-term systemic normobaric hypoxia. Eur J Clin Invest 46: 115-122, 2016.

ZENG S, FEIRT N, GOLDSTEIN M, GUARRERA J, IPPAGUNTA N, EKONG U, DUN H, LU Y, QU W, SCHMIDT AM, EMOND JC: Blockade of receptor for advanced glycation end product (RAGE) attenuates ischemia and reperfusion injury to the liver in mice. Hepatology 39: 422-432, 2004. 